\title{
GASTRIC FREEZING FOR DUODENAL
}

\author{
H. L. Duthie, M.D., Ch.M., F.R.C.S. \\ University Department of Surgery, The General Infirmary at Leeds
}

A CURE without recourse to surgery is the aim of all concerned with the treatment of duodenal ulcer. A new step in this direction was the introduction of gastric freezing by Wangensteen and his group in 1962 (Wangensteen, Peter, Nicoloff, Walder, Sosin and Bernstein, 1962b; Peter, Bernstein, Sosin, Madsen, Walder and Wangensteen, 1962). This relatively simple and apparently innocuous procedure had obvious attractions and has been pursued enthusiastically, especially in the U.S.A. However, the first flush of enthusiasm is now being tempered with some doubts and, in fact, there seems to be a definite swing away from gastric freezing. Much of this may be due to an uncritical and over-zealous approach in some quarters. A certain amount of the criticism is based on divergent results obtained in laboratory animals, some of which do not show any very obvious beneficial effect of gastric freezing. In this review the experimental basis of the technique is discussed along with the clinical results to date in the light of our limited experience.

\section{The experimental basis of gastric freezing}

Initial success with cooling of the stomach in the treatment of hæmatemesis led Wangensteen to consider further possibilities of gastric hypothermia. $\mathrm{He}$ also found that digestion of live frogs in the stomach of larger frogs or of dogs was arrested by cooling to 4 to $10^{\circ} \mathrm{C}$. Further extensive studies have been done to establish the safety and the efficacy of the method.

\section{Safety}

Wangensteen's group (Wangensteen, Peter, Bernstein, Walder, Sosin, and Madsen, 1962a) found in the dog that the critical temperature judged from the stand-point of absence of macroscopic evidence of injury to the gastric mucosa attending gastric freezing over a period of an hour was in the area of $-25^{\circ} \mathrm{C}$. However, they recommended using inflow temperatures of from $-17^{\circ} \mathrm{C}$. to $-20^{\circ} \mathrm{C}$. to give a margin of safety. In further studies they found that definite gastricwall necrosis occurred at an inflow temperature of $-30^{\circ} \mathrm{C}$, while this necrosis occurred in all animals subjected to freezing at an inflow temperature of -60 to $-80^{\circ} \mathrm{C}$.

Work at the Mayo Clinic did not show such a clear-cut safety margin between the recommended $\dot{0}$ temperatures and those producing necrosis (McIlrath, Hallenbeck, Allen, Mann, Baldes, Brown $\stackrel{9}{\rightarrow}$ and Rovelstad, 1963). In fact up to 5 days after $\vec{N}$ freezing definite ulceration of the mucosa was found $O$ in 7 of 10 dogs and 2 of 3 pigs who were treated at inflow temperatures of -16 to $-20^{\circ} \mathrm{C}$. Furthermore, in 2 of these dogs and in $I$ pig the necrosis extended through the full thickness of the gastric wall. Thus, dangerous damage was found at temperatures which were being used in man. support the latter workers. Of ro dogs treat with an inflow temperature of $-15^{\circ} \mathrm{C}$. the first three all showed mucosal ulceration when sacrificed $\bar{O}$ up to 6 days later. Modification of the balloon and perfusion system obviated this finding in the $\stackrel{\frac{\Omega}{\perp}}{\perp}$ remaining 7 dogs. No full thickness damage was $\overrightarrow{\vec{P}}$ observed.

Freezing of separated pouches of the stomach in the dog has resulted in 3 deaths due to hæmorr-? hage from ulceration of the pouch and 3 fistulæ: between pouch and intestine in a series of 253 . freezings (Savage, Stavney, Stevenson, Harkins and Nyhus, 1963).

\section{Efficacy}

Temperature attained. The temperature of the gastric mucosa was shown to be somewhere $\rightarrow$ between the inflow and outflow temperatures from the balloon for most of the perfusion time (Wangensteen and others, I962a). However, or later work did not confirm this observation $N$ and only at the end of an hour in a ro kg. dog did N this circumstance occur. In addition, using multiple thermistors registering temperature from 0 fundus, body and antrum of the stomach, it was observed that, for the first 20 minutes, freezing $\stackrel{\oplus}{+}$ point was not reached. When a pig weighing 0 $48 \mathrm{~kg}$. was used with a balloon containing $800 \mathrm{ml}$. of alcohol, at no time during the perfusion did the 
temperature of the gastric mucosa reach below $8^{\circ} \mathrm{C}$. This latter animal is of a comparable size to man and, as will be seen later, the perfusion conditions were similar (McIlrath and others, 1963). There remains the paradox that in these animals the areas where the thermistors were implanted did not achieve uniform freezing and yet sufficient freezing to cause full thickness damage of the stomach wall in other areas. The incompatibility of the results between these two groups of workers suggests that there are some differences in technique.

In common with other workers in this field we have observed on examination of the stomach at laparotomy after one hour's freezing that the cooling produced is patchy. Parts of the body may be quite hard and yet the antrum is rarely frozen by the present technique. Some of the hard patches may be explained by freezing of residual gastric content.

Depression of Function. Freezing of isolated gastric pouches in dogs has given some conflicting results. Depression of function has been observed (Wangensteen and others, 1962a), whether Heidenhain (vagally 'denervated') pouches were studied following a meal of meat or Pavlov (vagally innervated) pouches following the subcutaneous injection of Io units soluble insulin, or $0.2 \mathrm{mg}$. histamine base or testing by instillation of $100 \mathrm{ml}$. $10 \%$ peptone fed into the residual stomach. Freezing of isolated antral pouches diminished their gastrin release as measured by the acid response of Heidenhain pouches in the same animal. This failure of response has persisted up to 35 weeks. This group also found significant depression of acid secretion of the whole stomach in response to injection of insulin or the feeding of peptone in all I I dogs in whom the whole stomach was frozen.

Less uniform depression of function was demonstrated by Savage and others (1963) who tested 14 dogs after freezing of isolated Heidenhain pouches. Eight showed a diminished acid secretory response to the injection of $0.1-0.2 \mathrm{mg}$. histamine base or to a meal of liver. Of the remaining 6 , no change occurred in 4 and 2 had an increased acid output after freezing. It seems that other workers are having difficulty in getting adequate depression after freezing of total stomach preparations. For example, Gilat, Clapp, Sherlock, Cremer, Tayao, Lipkin and Almy (I963) found that acid secretion showed no significant suppression compared to pre-freezing levels in dogs within one week of freezing the intact stomach and at all subsequent post-freezing intervals studied. They studied secretion of acid in response to insulin, peptone and maximal histamine stimulation. Freezing was done by the Wangen- steen technique with an inflow temperature of $-20^{\circ} \mathrm{C}$. and an outflow temperature of $-12^{\circ} \mathrm{C}$. Other workers found that separated Heidenhain pouches made from the stomachs of dogs a week after freezing showed secretory characteristics within the range of normal for their laboratory (Meredith, Myers and Bradshaw, 1963).

Freezing an isolated pouch of the canine duodenum has been shown to inhibit the flow of pancreatic juice collected from the main pancreatic duct and excited by infusion of $20 \mathrm{ml}$. of $0.1 \mathrm{~N}$ hydrochloric acid into the isolated duodenum up to 90 days after freezing. The response of the pancreas to I.V. secretin was maintained so that direct damage to the pancreas had not occurred. The freezing was for periods of from to to 60 minutes at an inflow temperature of -17 to $-20^{\circ} \mathrm{C}$. (Goodale, Bernstein, Soucheray and Wangensteen, I963).

Protection Against Ulcer Formation. Freezing of the whole stomach protected dogs against iormation of ulcers when they were given daily injections of $30 \mathrm{mg}$. histamine in beeswax: six out of 12 control dogs developed ulcers within 60 days, whereas none was found in 5 dogs previously subjected to gastric freezing. Transplantation of the gastric antrum to the transverse colon with reconstitution of the alimentary canal by gastrojejunostomy was followed by ulceration at the jejunal stoma in $81.5 \%$ of control dogs and in only $10 \%$ of dogs aftergastric freezing (Wangensteen and others, 1962a).

\section{Structural Alterations}

Macroscopic. As was mentioned in the section on safety, damage to the gastric mucosa has resulted in ulceration after freezing and full thickness damage to the gastric wall has been reported. Patchy petechial hæmorrhage and wellmarked gastritis can be seen in the stomachs of most dogs treated by freezing.

Microscopic. The main report on this aspect of the subject is by Allcock, Carpenter, Bernstein, Peter and Wangensteen (1963). They examined specimens which were taken from 60 dogs on 93 occasions. Their work amplified the initial emphasis placed on the damage to parietal and mucus secreting cells showing as an abnormal granulity of the cytoplasm (Wangensteen and others, 1962a). The later studies revealed that cellular changes could be found through all layers of the gastric wall when specimens were taken from areas that had definitely been frozen. These changes resolved quite quickly and by 6 to 8 weeks following a single freezing the stomach of the dog was within normal histological limits.

Microscopic changes were most obvious in the superficial layers and in the early stages. $U_{p}$ to 
2 hours œdema is the only important change. Later loss of mucosa cells is shown which recovers in 48 hours if the lamina propria is intact. Damage to the neck cells may result in transient metaplasia with numerous goblet cells in the mucosa. Any breach in the mucosa is healed by regrowth from the gastric pits and is complete by 6 to 8 weeks. The parietal cells show their most obvious changes one to three days after freezing: the nuclei become pyknotic and the cells may be extruded into the tubular glands. Parietal cells tend to recover more slowly than chief cells or mucus-secreting cells.

Hyperæmia and infiltration with polymorphonuclear leucocytes is observed in the submucosa and varying degrees of damage to blood vessels have been noted. After recovery there is an increased amount of collagen in this layer. Changes in the muscular coats comprise mainly vacuolation of fibres with frank necrosis a rarity. If degeneration is present in the muscle, the ganglion cells of Auerbach's plexus in the area are altered: they lose the Nissl's granules and develop swollen pale nuclei. The serosa exhibits hyperæmia with some late fibrosis.

Repeated freezing 6 to 8 times results in longlasting aiterations in structure characterized by diffuse atrophy fibrosis and metaplasia of the mucosa with the appearance of obvious lymph follicles.

Studies of the rate of mucosal cell turnover in the stomach after gastric freezing have been made using tritiated thymidine to label the dividing nuclei. Cell renewal was revealed within two days and the turnover rate was normal within one week (Gilat and others, 1963). Thus the tendency to rapid repair noted by Allcock and others (1963) was confirmed.

\section{Method of gastric freezing \\ Machine}

A gastric freezing machine consists basically of a refrigeration unit and a pump. An ordinary domestic refrigerator unit has sufficient capacity for the temperature range required. Two firms, O.E.M. Division, Shampaine Industries, St. Louis, U.S.A. and Swenko Research and Development Co., Minneapolis, Minn., U.S.A., have had machines in production for over a year in U.S.A. and several others are becoming available. In the American models the pump runs at 1,725 r.p.m. and has a safety device to allow release of pressure in case of any block in the system. Another safety factor is the ability to release any air trapped in the circuit. This is obviously necessary when the gastric balloon is filled at the commencement of the procedure. In addition, any air leaking in through joints in the tubing has to be removed.
When such machines were used for gastric cooling at 5 to $10^{\circ} \mathrm{C}$. for 48 hours or more in the $\frac{a}{3}$ treatment of upper gastrointestinal hæmorrhage $\underset{\mathbb{Q}}{\mathbb{Q}}$ one of the early problems was trapping of air $c$. within the gastric balloon which could then expand without any interference with the perfusion $\stackrel{?}{\rightarrow}$ system: there was a danger of overdistension of $\bar{C}$ the stomach. However, an air-bleed safety device $\frac{\bar{\sigma}}{\bar{D}}$ is now on the American machines even though $\frac{\bar{\sigma}}{\sigma}$ the risk on a treatment lasting about an hour $\stackrel{\mathbb{\Omega}}{\varrho}$ must be slight.

\section{Balloon}

In distinction to the relative simplicity of the $\overrightarrow{\vec{H}}$ machine the development of a satisfactory balloon $\omega$ to provide an even contact with the gastric mucosa is still evoking much research both in U.S.A. and 3 in this country. The standard balloon used is of heavy latex rubber shaped roughly to conform to the outlines of the stomach. It is only slightly distended by the volume of 600 to $800 \mathrm{ml}$. of coolant which is normally used in treacment. 0 Even with this balloon it is almost impossible to 음 maintain flow patterns which would provide a uniform temperature at all parts of the surface. Obviously the parts nearest the inflow points will be cooler than the extremities of the balloon. How much more difficult would it be to achiev $\vec{\emptyset}$ an even temperature if a balloon were made wit folds and grooves to attempt to accommodate the gastric rugæ.

A theoretical solution would be to dispense with the balloon and to have the coolant circulating in the stomach itself with small balloons occluding the pylorus and the cardia. Attempts are being made to find a non-toxic fluid or a gas which could be used. At present $95 \%$ alcohol is used to fill the balloon.

\section{Procedure}

After an overnight fast the patient is sedated and a local anæsthetic applied to the pharynx. Thereafter, the balloon is passed on the end of a double lumen tube $0.8 \mathrm{~cm}$. in external diameter. The diameters of the lumina alter the rate of flow of the coolant which is usually about I to 1.5 은 litres per minute with the standard tubing. About $D$ $200 \mathrm{ml}$. of alcohol is run into the balloon to open it out slightly and the tubing is withdrawn until o the resistance of the cardia is felt. More alcohol is then run slowly into the balloon until the patient feels a fullness in the epigastrium; by this time the volume is about 600 to $800 \mathrm{ml}$. Perfusion is then commenced and lasts for from 40 to 60 minutes. When the flow is stopped the balloon is left in situ for ro minutes or so to allow thawing: it is then emptied and withdrawn. During the perfusion the patient has no discomfort except tendency to shivering towards the end of the 
treatment. He is provided with an electric blanket or extra bed coverings.

The duration of perfusion and the temperature of the alcohol have been varied from time to time. To begin with most attention was paid to the temperature at which the fluid was put into the balloon but now the emphasis is on the outflow temperature. This makes allowance for the differing heat exchange in patients of different build. At present, we use an outflow temperature of $-10^{\circ} \mathrm{C}$. for 50 minutes. Another parameter which will require calibration is the flow rate during the procedure as the amount of cooling also depends on it.

\section{Results in man}

\section{Effect on Symptoms}

The early results from Wangensteen's group show an immediate relief of symptoms in about $85 \%$ of cases. Over I,000 patients have been treated in Minneapolis. The duration of relief has not yet been established: this is the crucial test of the benefit of the method. Already some patients have had to be frozen two or three times.

\section{Side Effects}

Mortality. One death has been reported (Welch, 1963).

Morbidity. As might be expected from the work on dogs gastric ulceration has occurred in some patients. Seventeen were reported in a series of over 900 from Minneapolis (Bernstein, 1963). Initially this was thought to be due to a 'cold spot' caused by a jet of alcohol from the end of the inflow tube: changing this jet to a spray has not completely avoided this complication. Another serious complication is melæna. This has been severe enough to require transfusion and even surgery but most cases are slight. A positive test for fæcal occult blood is found in all patients tested after freezing and about $40 \%$ show a loss of $10 \mathrm{ml}$. or more of blood as measured by labelling red blood cells with radiochromium $\left({ }^{51} \mathrm{Cr}\right)$ (Hightower, 1963). Pyloric stenosis occurred following gastric freezing in some of the initial patients and any degree of pyloric hold-up is considered as a contra-indication.

During the freezing the patient has little or no discomfort. However, some shoulder-tip pain the next day has been complained of and along with a pyrexia of up to $102^{\circ} \mathrm{F}$. may occur a leucocytosis of up to $16,000 / \mathrm{cu}$. mm. Patchy gastritis has been evident as much as 3 months after freezing in a few of the patients studied with the gastroscope (Colcher, Smith and Wangensteen, 1963).

\section{Effect on Gastric Function}

The depression of gastric acid secretion in man after gastric freezing shows a tendency to return to normal within 3 months. For example, Bernstein (1963) reported that $50 \%$ of patients have achlorhydria in the 12 -hour overnight unstimulated gastric secretion immediately after freezing: this figure is only $11 \%$ at 12 weeks and none is achlorhydric at 6 months. Stimulation of the gastric juice with histalog (Hightower, 1963) or intravenous infusion of histamine (Forrest, 1963: Duthie, 1963) does not show such a marked inhibition and the return to normal is more rapid.

Much research into the basic problems of the method is being done in U.S.A. and at several centres in this country. Controlled trials of the clinical efficacy of gastric freezing are under way, notably a multiple-centre trial arranged in five American university groups. Further experience is rapidly being accumulated in other units, especially at Minneapolis. Further clarification of the situation should not be long delayed.

\section{Comment}

Any new form of treatment is only established when its safety and efficacy can be assessed. Despite somewhat alarming degrees of damage produced in experimental animals the method seems relatively safe in man. However, the definite morbidity attendant on the method means that it will have to be fully effective to be worth while.

Not so encouraging are the reports on secretory function in dogs and in man. While isolated canine pouches may be inhibited for up to 35 weeks it would seem that they would be susceptible to a more complete and uniform freezing as there is a much better chance of even application of the mucosa to a balloon. This would also be true of human stomach remnant after gastric resection and stomal ulceration has been treated by gastric freezing with initial success (Bernstein, McFee, Goodale, Madsen and Wangensteen, I963). More difficulty has been experienced in depressing the function of the whole stomach by freezing and the rapid return of acidity to pre-freezing levels in man would suggest that remissions from a single freeze may not last many months.

The lack of uniformity of cooling of the stomach by the present technique together with the failure to lower its temperature to freezing point in some tests, would suggest that some modification is necessary before a final verdict can be given. Many workers are attempting to produce a better system and none more vigorously than the Minneapolis group. If the balloon could be dispensed with many of the difficulties would be avoided. Let us hope that a non-toxic liquid can be discovered which will stay fluid at $-20^{\circ} \mathrm{C}$. Obviously when a more sophisticated method is produced the whole position will have to be reassessed. 
I thank Dr. O. H. Wangensteen and his co-workers for providing full details of the laboratory and clinical experience with gastric freezing during my visit to Minneapolis, also Dr. McIlrath and colleagues at the Mayo Clinic and Dr. S. L. Wangensteen and associates at the Presbyterian Hospital, New York. The expenses of purchasing our gastric freezing machine were met in part by a grant from the Endowment Fund of the $\bar{D}$ Board of Governors of the General Infirmary at 2 Leeds.

\section{REFERENCES}

Allcock, E. A., Carpenter, A. M., Bernstein, E. F., Peter, E. T., and Wangensteen, O. H. (1963): Structura Changes Following Gastric Freezing, Surgery, 53, 764 .

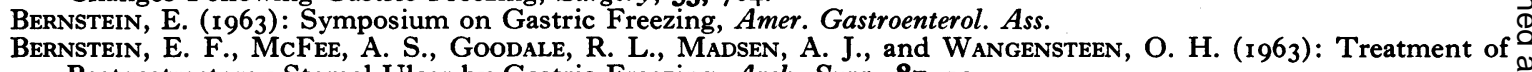
Postgastrectomy Stomal Ulcer by Gastric Freezing, Arch. Surg., 87, 13.

Colcher, H., SMith, R., and WAGENSTEEN, S. L. (1963): Postfreezing Gastritis: Gastroscopic Findings, Gastroenterology, 44, 821 .

DutHIE, H. L. (1963): Unpublished Observations.

FORREST, A. P. M. (1963): Personal communication.

Gilat, T., Clapp, P., Sherlock, P., Cremer, J., Tayao, M., Lipkin, M., and Almy, T. P. (1963): Effects of Freezing on Gastric Mucosa in Dogs, Gastroenterology, 44, 862.

Goodale, R. L., Bernstein, E. F., Soucheray, J., and Wagensteen, O. H. (1963): Effect of Duodenal Freezing on 3 . the Secretin Mechanism, Proc. Soc. exp. Biol. (N.Y.), 112, 738.

HallenBeCK, G. A. (1963): Symposium on Gastric Freezing, Amer. Gastroenterol. Ass.

Hightower, N. (1963): Symposium on Gastric Freezing, Ibid.

R. A. (1963): Gastric Freezing: An Experimental Study, Gastroenterology, 45, 374.
Meredith, J. H., MYers, R. T., and BRADSHAW, H. H. (1963): Acid Secretion in Stomach Pouches made after Freezing $\vec{N}$ the Stomach, Ann. Surg., 158, 440.

Peter, E. T., Bernstein, E. F., Sosin, H., Madsen, A. J., Walder, A. I., and Wangensteen, O. H. (1962): Technique of Gastric Freezing in the Treatment of Duodenal Ulcer, F. Amer. med. Ass., 181, 760.

Savage, L. E., Stavney, L. S., Stevenson, J. K., Harkins, H. N., and Nyhus, L. M. (1963): Secretory Studies in Frozen Heidenhain Pouches, Arch. Surg., 87, 690.

Wangensteen, O. H., Peter, E. T., Bernstein, E. F., Walder, A. I., Sosin, H., and Madsen, A. J. (1962a): Can $⿱ 乛$ 丂 Physiological Gastrectomy be Achieved by Gastric Freezing? Ann. Surg., 156, 579.

Wangensteen, O. H., Peter, E. T., Nicoloff, D. M., IWalder, A. I., Sosin, H., and Bernstein, E. F. (1962b\$ Achieving 'Physiological Gastrectomy' by Gastric Freezing, F. Amer. med. Ass., 180, 439.

Welch, C. E. (1963) Gastric Hypothermia, New Engl. 9. Med., 268, 33 I. 